This is a post-peer-review, pre-copyedit version of an article published in Journal of Mechanical Science and Technology. The final authenticated version is available online at: http://dx.doi.org/10.1007/s12206-018-08 -y 


\title{
Effect of Nozzle Rotation Angles and Sizes on Thermal Characteristic of Swirl Anti-Icing
}

\author{
Mohd Azmi Ismail ${ }^{1 *}$, Jian Wang ${ }^{2}$ \\ ${ }^{1}$ School of Mechanical Engineering, Universiti Sains Malaysia, Malaysia \\ ${ }^{2}$ School of Aerospace and Aircraft Engineering, Kingston University London
}

\begin{abstract}
The Federal Aviation Administration requires all aircraft manufacturers to adhere to maximum noise level standards. Thus, a Bias Acoustic Liner is introduced, to intensify the noise equipment system, as well as prevent ice accumulation on the nacelle D-chamber. The hotspot phenomenon, by the Piccolo Tube Anti-Icing system, could damage the Bias Acoustic Liner. Therefore, a Swirl AntiIcing system is further investigated, to reduce the hotspot effect on the Bias Acoustic Liner. The present work investigates the effect of nozzle rotation angles at various mass-flow-rates of hot-air supplied on the nacelle lip-skin temperature distribution, in order to enhance the Swirl Anti-Icing system's performance. The effect of the nozzle ratio area on the swirl anti-icing system's performance to be discussed in the present work. The simulation results show that the hotspot temperature decreases by $26 \%$ and the cold spot temperature increases by $18 \%$, as the nozzle to be rotated from $0^{\circ}$ to $13^{\circ}$ towards the inner skin. However, the nozzle ratio area shows a negative effect on the swirl anti-icing performance, where the hotspot temperature increases by $6.7 \%$ and the cold spot temperature decreases by $30.2 \%$ with the ratio nozzle area increasing from 0.1083 to 0.8354 . According to Swirl Anti-Icing empirical values, the average Nusselt number is directly proportional to the average Reynolds number. In conclusion, the temperature distribution on the nacelle lip-skin and the Swirl Anti-Icing system's performance improves as the angle of nozzle direction increases, rotating towards the inner skin. Swirl Anti-Icing does not generate hotspot on the inner skin, thus making it suitable for use in a Bias Acoustic Liner system.
\end{abstract}

Keywords: Cold-spot; Hotspot; Nusselt number; Nacelle lip-skin; Reynolds Number; Swirl Anti-Icing.

\section{Introduction}

Since an increase in the number of aircraft is accompanied by increasing noise levels, the Federal Aviation Association has issued aircraft noise-level standards to which all aircraft manufacturers must adhere. There are several possible approaches to reducing noise produced by engines and turbines, e.g. installation of an acoustic liner (AL) in a noise cowl zone. Actually, nose cowl zones have limited space, but Lucas [1] suggested installing a noise abatement system on a nacelle leading edge. The combination of an acoustic liner and anti-icing on a nacelle leading edge may not be able to reduce the forward radiated noise and to improve the antiicing system's thermal performance easily. Therefore, a Bias Acoustic Liner (BAL) is installed in that limited space, in order to overcome the non-uniformity of the heat transfer to the nacelle lip cowl zone [2].

Piccolo Tube Anti-Icing (PTAI) is the most efficient and reliable method for preventing ice accumulation on aviation critical surfaces [3], but non-uniform heat transfer occurs on nacelle lip-skins, since hotspots and cold-spots have the maximum heat transfer rate and the minimum heat transfer rates on nacelle lip-skin, respectively. As a consequence, ice

\footnotetext{
${ }^{\dagger}$ This paper was recommended for publication in revised form by Associate Editor 000 000-please leave blank.

${ }^{*}$ Corresponding author. Tel. +6045996319 , Fax.: +6045941025
}

accumulates downstream from the nacelle lip-skin area. The complexity of the PTAI systems results in high manufacturing costs. Thus, a Bias Acoustic Liner (BAL) is introduced into Swirl Anti-icing (SAI) [4] to minimize hotspots and cold-spots on the nacelle lip-skin. This arrangement provides uniform and better heat distribution, compared to PTAI, and also has fewer components, with lightweight and simple plumbing.

Many researchers use a Computational Fluid Dynamic (CFD) code, due to the complexity of the anti-icing experiments and the flight tests. Keith et al. [5] analyzed the performance of hot-air anti-icing as an engine inlet ice protection method. Based on the results, the authors suggested that the heat should be focused on the stagnation point, in order to evaporate water droplets. Smith and Taylor [7] employed the PHEONICS code, to simulate a 2-D antiicing system on a nacelle lip-skin in dry and wet conditions. For simplification purposes, they neglected the heat transfer coefficient on the water impinging on the surface. They claimed that their simulation results were in good agreement with flight test data. Hua and Liu [8], Planquart et al. [9], Papadakis and Wong [10], and Wong et al. [11], optimized the thermal performance of anti-icing systems. They concluded that the simulation results were in good agreement with experimental data. In 2016, Azam et al. [13] developed a 2D CFD model to investigate the effect of the BAL on the drag coefficient. Based on their simulation results, the BAL has the potential to reduce the drag coefficient of the nacelle lip-skin. CFD can also be used to predict a wind turbine's 
aerodynamic performance. Mo and Lee [12] observed 3-D stall occurring close to blade root at wind speed of $7 \mathrm{~m} / \mathrm{s}$. Afterwards, as the wind speed increased, the 3-D stall separated from the blade root. In addition, the CFD is also widely used in heating, ventilation, and air conditioning (HVAC). For instance, Jung et al. [6] used the CFD to improve the performance turbo blower in strong vortex conditions. Turbo blowers are widely used to enhance the HVAC performance. According to their CFD results, the final design has better static pressure and static fans efficiency than previous designs, due to the elimination of vortex regions on the vaneless diffuser's shroud.

Based on the studies mentioned above, the CFD was chosen as a tool to predict SAI thermal characteristics. The hotspot temperature and the cold-spot temperature are the main characteristics in the present work as the indicators of temperature deviation on the nacelle lip-skin surface. If the temperature difference between hotspot and cold-spot is too high, the potential of runback ice accretion on downstream nacelle lip-skin surface is very high. Runback ice accretion has several negative effects on commercial aircraft, including high drag coefficient, high fuel consumption, and aircraft crash. Average lip-skin temperature is an indicator of antiicing performance efficiency, with higher average nacelle lip-skin temperature indicating higher nacelle anti-icing efficiency, at a given heat supplied to the anti-icing system. The paper also compares our simulation results and the experimental results obtained by Rosenthal and Nelepovitz [14]. Also, SAI improvement was studied by varying the nozzle rotation angle (NRA) and nozzle ratio area. The present work also will present an empirical correlation based on the simulation results.

\section{Model Description}

The small nacelle lip-skin used in this study is commonly utilized in commercial aircraft. This nacelle has a diameter of $0.6731 \mathrm{~m}$, and a D-chamber with a cross-sectional area $\left(A_{D-}\right.$ chamber) of $0.006066 \mathrm{~m}^{2}$. The operating conditions are shown in Table 1. The nacelle inlet lip, the nozzle, and the bulkhead are built from aluminium, stainless steel, and titanium, respectively. This information was obtained from Rosenthal [14], with the exception of the free stream velocity.

Table 1. Summary of operating conditions

\begin{tabular}{c|c}
\hline Conditions & Magnitude \\
\hline $\begin{array}{c}\text { Ambient Temperature } \\
\text { Mass flow rate of hot air to D- } \\
\text { chamber }\end{array}$ & $-6.667^{\circ} \mathrm{C}$ \\
\hline
\end{tabular}

\begin{tabular}{c|c}
\hline $\begin{array}{c}\text { Maximum velocity of the nozzle jet } \\
\text { Maximum Mach number of the } \\
\text { nozzle jet }\end{array}$ & 107 to $710 \mathrm{~m} / \mathrm{s}$ \\
Temperature of hot air inside & 0.3 to 2.10 \\
nozzle & $260^{\circ} \mathrm{C}$ \\
Ambient pressure & $96497 \mathrm{~Pa}$ \\
Free Stream velocity & $48.75 \mathrm{~m} / \mathrm{s}$ \\
Ambient Mach number & 0.149 \\
\hline
\end{tabular}

The SAI system in the present study contains 10 exhausts, all semicircular with a diameters of $0.0381 \mathrm{~m}$, as shown in Fig. 1 . The pipe penetrates the bulkhead in the $135^{\circ}$ plane from the top D-chamber. The exhausts/pressure outlets are located on the bulkhead, $30^{\circ}$ apart. Each one is also plus or minus $45^{\circ}$ from the nozzle entry point.

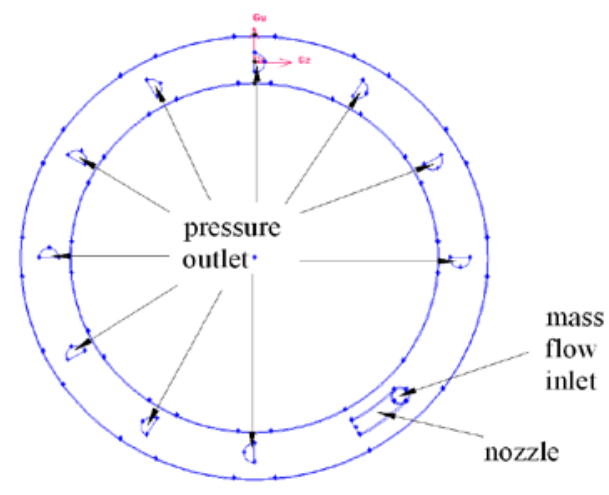

Fig. 1. Boundary swirl anti-icing conditions

\section{Computational Setup}

An ANSYS workbench 17.2 was used to create a model. A high-density air mesh was employed in the high-pressure gradient domains, including effective-impingement-surface and nozzle vicinities, to ensure accurate results. In addition, the dimensions of the ambient domain were 16 times larger than the typical nacelle D-chamber dimensions (as shown in Fig. 2a). Pressure-far-field and pressure outlet are used to control the ambient-free-stream's Mach number.

Fig. 2b illustrates boundary conditions inside the nacelle lip-skin. Space inside the nacelle lip-skin nozzle is used to contain the hot air mass flow rate to the D-chamber. A massflow-inlet is utilized at the nozzle entrance, to control the hot air mass flow rate $\left(\dot{m}_{\text {nozzle }}\right)$. A pressure outlet is set up on the exhaust surfaces, to release the exhausted air from the Dchamber. Pressure outlet was extended to cover the distance by 8 times the outlet diameter in order to avoid back flow inside D-chamber. Bulkheads at the rear nacelle and the exhaust duct were set as a wall. The nacelle lip-skin and the nozzle walls were considered non-adiabatic, in order to allow the heat transfer from the hot air to the ambient, and the remaining walls were assumed to be adiabatic. The wall temperature depends entirely on $\dot{m}_{\text {nozzle }}$ and the ambient temperature. In the present work, the nacelle lip-skin wall temperature falls in the range between $1^{\circ} \mathrm{C}$ and $190^{\circ} \mathrm{C}$.

The present study utilizes a FLUENT CFD [12] code to obtain simulation results. The flow is compressible and turbulent, as the jet Mach numbers and the average Reynolds 
numbers $\left(R e_{\text {ave }}\right)$ exceed 0.3 and 80,000 , respectively. $K$ omega shear stress transport (SST) is selected, such that the turbulence model takes the transport of the turbulent shear stress into account [15].

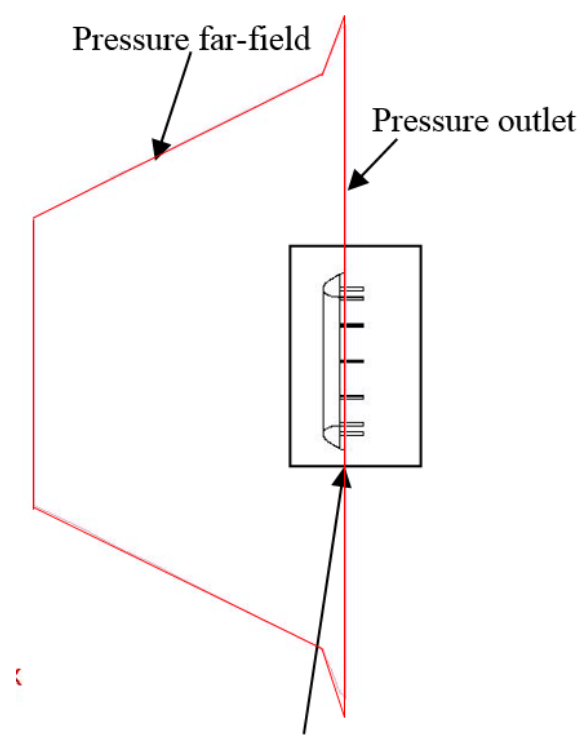

Nacelle lip-skin vicinity

Fig. 2a. The swirl anti-icing boundary conditions (outside the nacelle lip-skin)

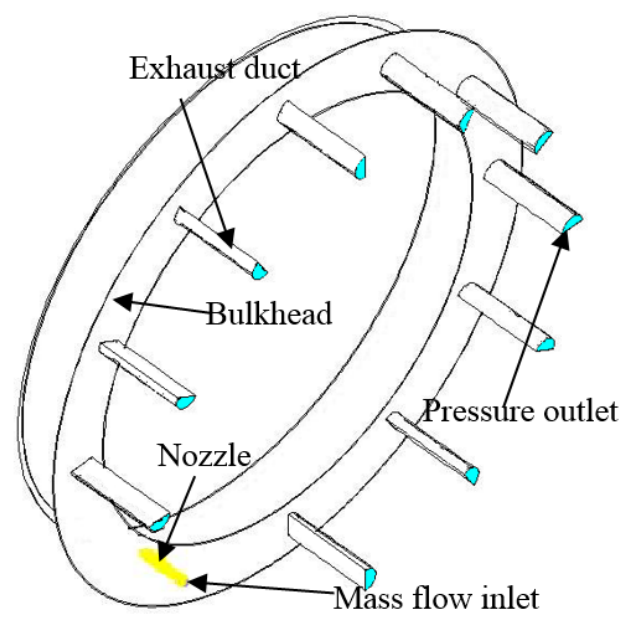

Figure 2b.Boundary conditions inside the nacelle lip-skin (nacelle lipskin removed)

\section{Grid Independence Test}

The grid independence test was conducted before examining the SAI performance. Three different numbers of meshes were used: 3,000,000 (coarse mesh), 4,750,000 (fine mesh), and 7,000,000 (very fine mesh). The dimensionless temperature $(\dot{T})$ in the present investigation is calculated by using Eq. (1)

$$
\dot{T}=\frac{T_{y}-T_{\infty}}{T_{\text {nozzle }}-T_{\infty}}
$$

The local temperature $\boldsymbol{T}$ distributions on the nacelle lip- skin for both models, in two different planes, $180^{\circ}$ and $270^{\circ}$, are plotted in Fig. 4. The wrap location (\%) is used to describe the results, which are illustrated in Fig. 5. Fig. 3 illustrates the position of the plane on the nacelle.

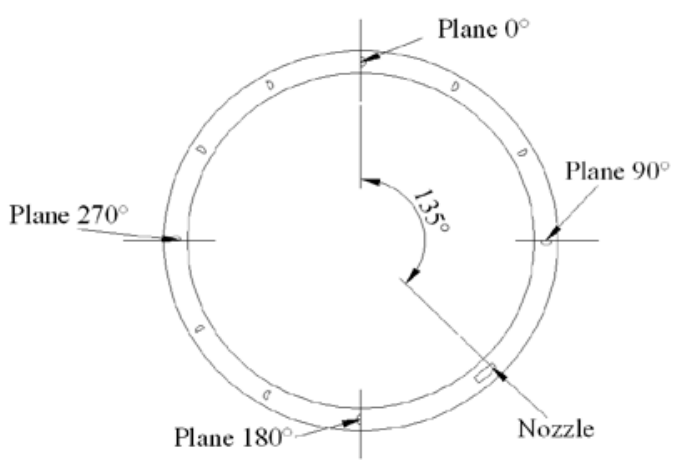

Fig. 3. Plane position on the nacelle lip-skin

As shown in Fig. 4, the local $\dot{\boldsymbol{T}}$ curves for the fine mesh in both planes are similar to the local $\dot{\boldsymbol{T}}$ curves for the very fine mesh. However, the local $\dot{\boldsymbol{T}}$ values for the coarse mesh are significantly lower than those for both fine and very fine meshes in both planes. The greatest local $\dot{\boldsymbol{T}}$ difference between the fine and the very fine meshes in plane $180^{\circ}$ is 0.00337 (less than $2 \%$ ) and occurs at the wrap location of $14 \%$. Finally, the wall spacing distance $\left(y^{+}\right)$was set at 2 , which is lower than 5 or the highest $\mathrm{y}+$ in lamina sub-layer [16]. In order words, the first element layer is inside the boundary layer lamina sub-layer. Therefore, the fine mesh is used in the subsequent study, as the fine mesh has an acceptable $\mathrm{y}^{+}$.

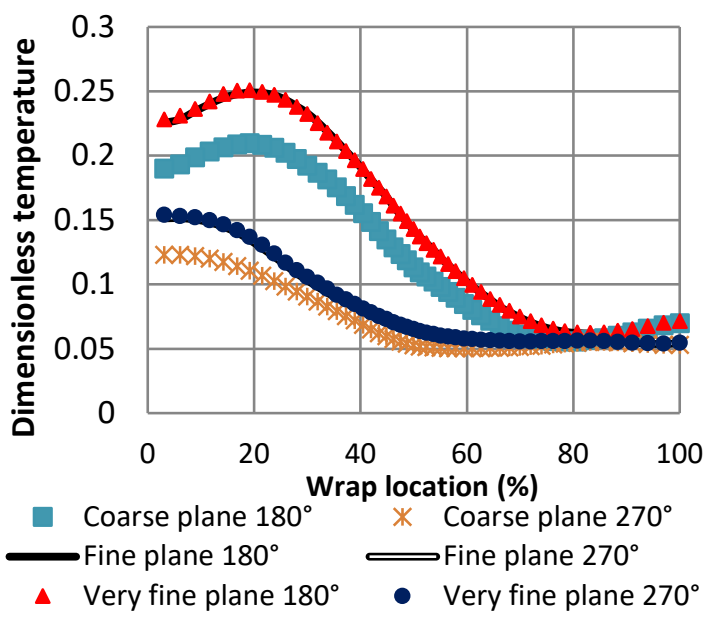

Fig. 4. Local dimensionless temperature profile along the wrap location, for course, fine and very fine meshes 


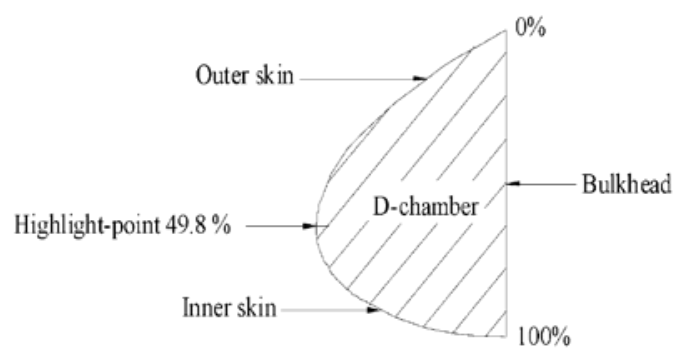

Fig. 5. The wrap location position on the nacelle D-Chamber.

\section{Validation}

The simulation results are compared to the experimental data collected by Rosenthal and Nelepovitz [14], by using the ratio $A_{\text {nozzle }} / A_{D \text {-chamber }}$ of 0.01083 . The prototype used by Rosenthal and Nelepovitz has the inlet diameter of $2.44 \mathrm{~m}$, which is 3.6 times larger than that of the inlet used in the present work. However the nacelle profiles for both studies were similar. Therefore, two of the parameters, namely, the hot air injection mass flow rate/ area of D-chamber or the swirl ratio ( $\dot{\boldsymbol{m}}_{\text {nozzle }} / \boldsymbol{A}_{\boldsymbol{D} \text {-chamber }}$ ), and the ratio of the average air flow rate inside D-chamber to the hot air injection mass flow rate $\left(\dot{\boldsymbol{m}}_{\boldsymbol{s w}} / \dot{\boldsymbol{m}}_{\text {nozzle }}\right)$, were used in this comparison. The other parameters studied by Rosenthal and Nelepovitz were the same as those listed in Table 1, with the exception of free stream velocity and ambient temperature. The free stream velocity and the ambient temperature in Rosenthal and Nelepovitz's study were $0 \mathrm{~m} / \mathrm{s}$ and $15^{\circ} \mathrm{C}$, respectively since the experiment was conducted inside laboratory and outside a wind tunnel. Therefore, the dimensions of the present simulation nozzle were also 3.6 times smaller than the dimensions of the nozzle used by Rosenthal and Nelepovitz. In their study, the $\dot{\boldsymbol{m}}_{\text {nozzle }} / \boldsymbol{A}_{\boldsymbol{D} \text {-chamber }}$ ranged from 0.41 to 3.71 . As Fig. 6 shows, the simulation results are in excellent agreement with Rosenthal and Nelepovitz's data at $\dot{\boldsymbol{m}}_{\text {nozzle }} / \boldsymbol{A}_{\boldsymbol{D} \text { - }}$ chamber values ranging between 0.41 and 3.71 .

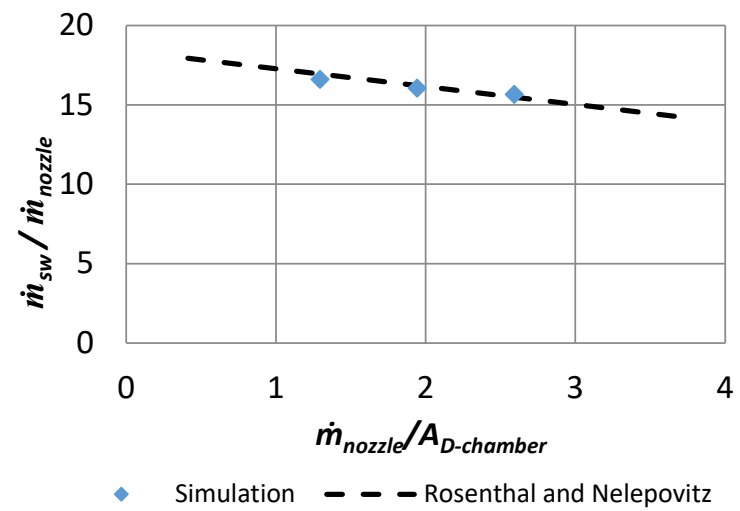

Fig. 6. Comparison between the current simulation study and the results collected by Rosenthal and Nelepovitz [14]

\section{Results and Discussion}

As Fig. 7 demonstrates, the hotspot and the cold-spot locations can be seen at A and B, respectively. The hot air injection from the nozzle results in a hotspot, and then strikes it directly at point $\mathrm{A}$. The maximum heat transfer at this spot is due to very thin thermal and hydraulic boundary layer. After the hot air strikes the outer skin, the flow changes its' direction along the nacelle D-chamber's outer skin. The jet flow is split, due to the velocity and the temperature differences between the hot air from the nozzle and the cold air in the D-Chamber. This enhances the heat transfer, and the mixing between the hot air and the cold air in the Dchamber. Afterward, the hot air is oscillated, and follows the lip-skin in forwarding mixing. When the hot air completely reverses its' direction from the nozzle, cold spots may form at point $\mathrm{B}$. In addition, due to the lower swirling air velocity and the lower temperature adjacent to the inner skin than those adjacent to the outer skin, the inner skin has a lower temperature than the outer skin along the nacelle lip-skin.

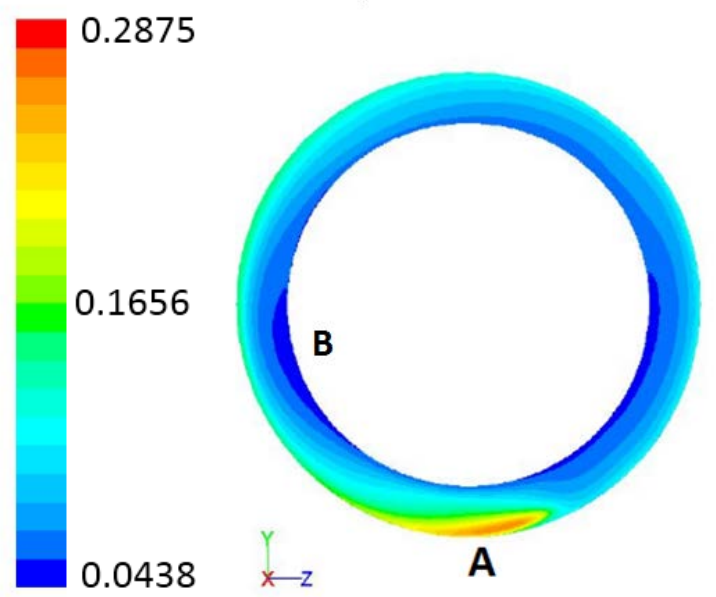

Fig. 7. Nacelle lip-skin dimensionless temperature contour in the original position.

Fig. 8 shows dimensionless temperature $\boldsymbol{T}$ profiles against the wrap location in four different planes, to demonstrate the temperature distribution along the nacelle lip-skin. In the present study, lower hotspot dimensionless temperatures $(\dot{\boldsymbol{T}})$, higher cold spot $\dot{\boldsymbol{T}}$ values and higher average lip-skin $\dot{\boldsymbol{T}}$ values indicate higher SAI performance, since anti-icing designs aim for low hotspot temperatures, high cold-spot temperatures, and high average lip-skin temperatures.

In plane $170^{\circ}$, the $\dot{\boldsymbol{T}}$ increases to the peak $\dot{\boldsymbol{T}}$, then decreases to the lowest $\dot{\boldsymbol{T}}$ before increasing again slowly, until it reaches the wrap location of $100 \%$. The figure also shows that $\dot{\boldsymbol{T}}$ in plane $270^{\circ}$ decreases with increasing wrap location, before levelling off at $60 \%$ and remaining nearly constant until the wrap location of $100 \%$. Planes $0^{\circ}$ and $90^{\circ}$ are behind the nozzle, and have a more uniform local temperature distribution, where the temperature decreases gradually as the wrap location increases from $0 \%$ to $74 \%$. Then, the temperature increases slowly against the wrap location, until the wrap location reaches $100 \%$. As expected the local temperature of plane $90^{\circ}$ is lower than that of plane $0^{\circ}$ along the entire wrap location. 


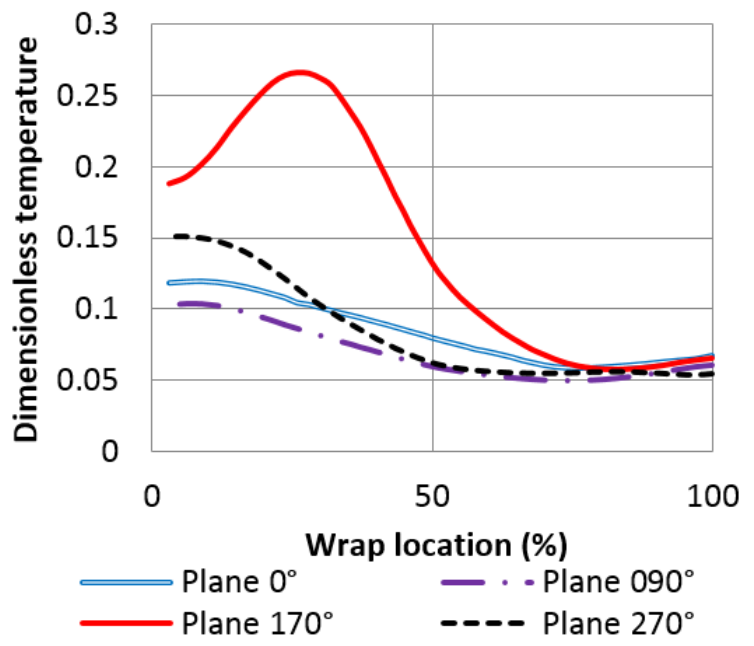

Fig. 8. The nacelle lip temperature profile in several planes at the rotation of $0^{\circ}$

Figure 9 explains why the temperature at wrap location values below $50 \%$ is higher than that at wrap locations values above 50\%. According to Fig. 9, the Mach number of the hot air adjacent to the nacelle lip-skin wrap location with values below $50 \%$ is higher than that of the hot air adjacent to the nacelle lip-skin wrap locations with values above 50\%. Therefore the heat transfer coefficient at wrap location values below $50 \%$ is higher than that at wrap locations with values above 50\%. As the result, $\dot{\boldsymbol{T}}$ in wrap locations below $50 \%$ is higher than $\dot{\boldsymbol{T}}$ in wrap locations above $50 \%$. The $\dot{\boldsymbol{T}}$ in plane $170^{\circ}$ is higher than that of the others, due to the hotspot occurring in Plane $170^{\circ}$, or Point A, as illustrated in Fig 8.
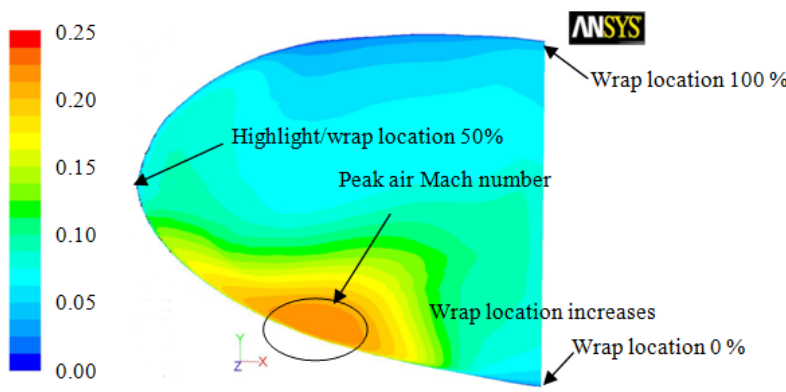

Contour of Mach number

Fig. 9. Mach number contour in Plane $170^{\circ}$

\subsection{Effect of nozzle rotation angle (NRA) to SAI performance}

The SAI direction modification is simulated in this study, to enhance the SAI performance. More uniform temperature distribution, lower hotspot $\dot{\boldsymbol{T}}$, and higher cold spot $\dot{\boldsymbol{T}}$ indicate better SAI, or anti-icing, performance. Thus, the study monitors the effects of five nozzle rotation angles (NRA); namely, $0^{\circ}, 5^{\circ}, 7^{\circ}, 9^{\circ}$, and $13^{\circ}$, towards the inner skin as illustrated in Fig 10, on the lip-skin temperature distribution.

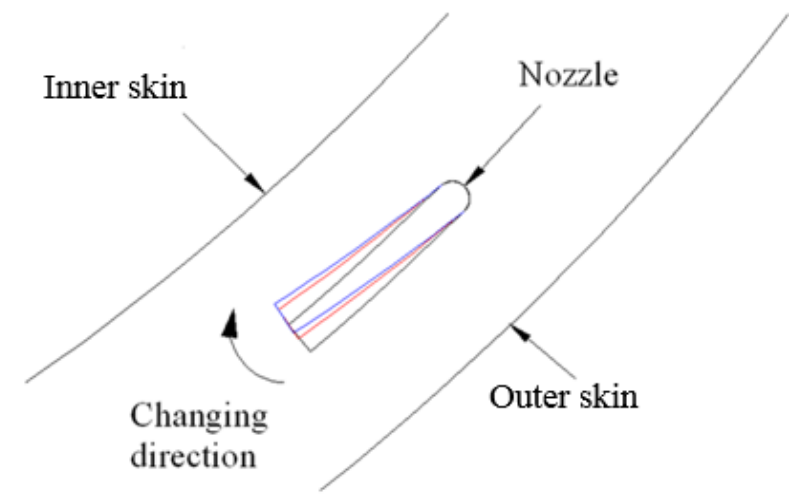

Fig. 10: Illustration of nozzle rotation angle

The effect of nozzle rotation angles of $0^{\circ}$ and $13^{\circ}$ towards the inner skin on the temperature contours are shown in Figs. 7 and 11, respectively. According to the figures, the hotspot position moves from point A (see Fig. 7) to point C (see Fig. 11). As expected, the lip-skin temperature distribution at NRA $13^{\circ}$ is significantly more uniform than at the original nozzle position.

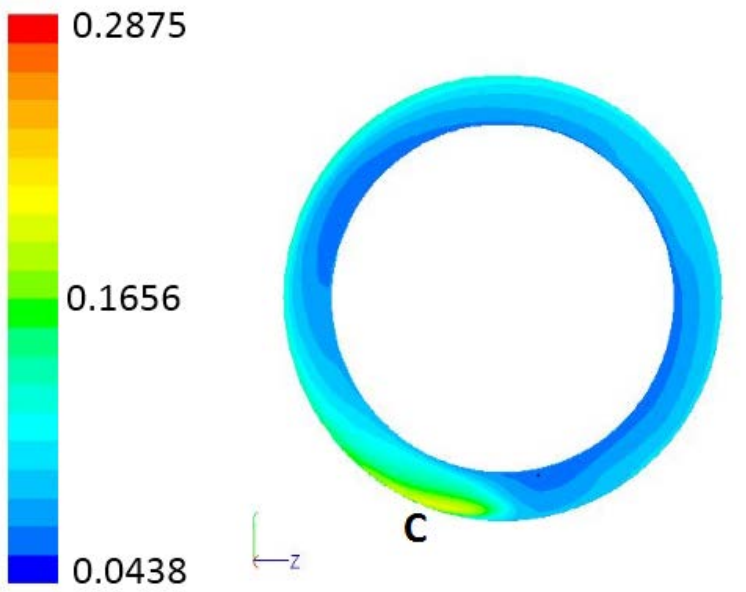

Fig. 11 Nacelle temperature contour at the NRA of $13^{\circ}$.

Fig. 12 illustrates the effects of the NRA on the hotspot $\dot{\boldsymbol{T}}$, the cold-spot $\dot{\boldsymbol{T}}$, the average $\dot{\boldsymbol{T}}$, and the $\dot{\boldsymbol{T}}$ differences between hotspot and cold-spot. The figure shows that the $\dot{\boldsymbol{T}}$ of the hotspot and the $\dot{\boldsymbol{T}}$ difference between hotspot and cold-spot are inversely proportional to the NRA. However, the coldspot $\dot{\boldsymbol{T}}$ and the average $\dot{\boldsymbol{T}}$ increase gradually with the increasing NRA. As the $\dot{\boldsymbol{T}}$ difference between the hotspot and cold spot decreases, the $\dot{\boldsymbol{T}}$ distribution on the nacelle lip-skin becomes more uniform. As the result, the potential of runback ice accretion is reduced significantly which is good for aircraft. The lip-skin's average $\dot{\boldsymbol{T}}$ increases with the increasing NRA, indicating that the efficiency of the heat supplied to the anti-icing system also increases with the increasing NRA. Therefore, the anti-icing system's efficiency is enhanced as the NRA increases. In conclusion, increasing the NRA enhances the SAI system's performance. 


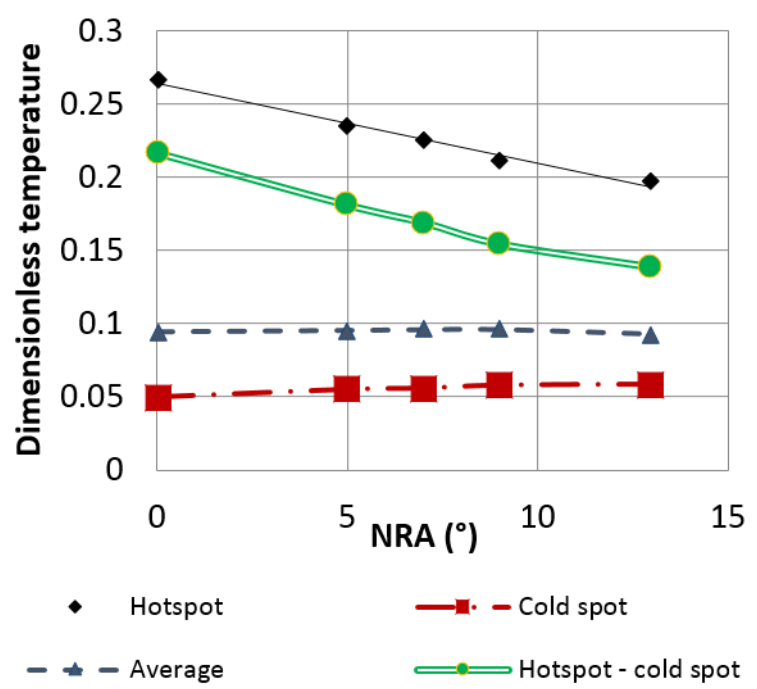

Fig. 12. Effect of NRA on hotspot, cold spot, and average lip-skin temperature.

The $\dot{\boldsymbol{T}}$ distribution in hotspot and cold-spot planes is shown in Fig. 13. The figure is used to investigate the temperature uniformity in the nacelle lip-skin. Increasing the NRA enhances the SAI performance in both planes. As Fig.13 demonstrates, the SAI performance is better at NRA $13^{\circ}$ than at NRA $0^{\circ}$ in both planes.

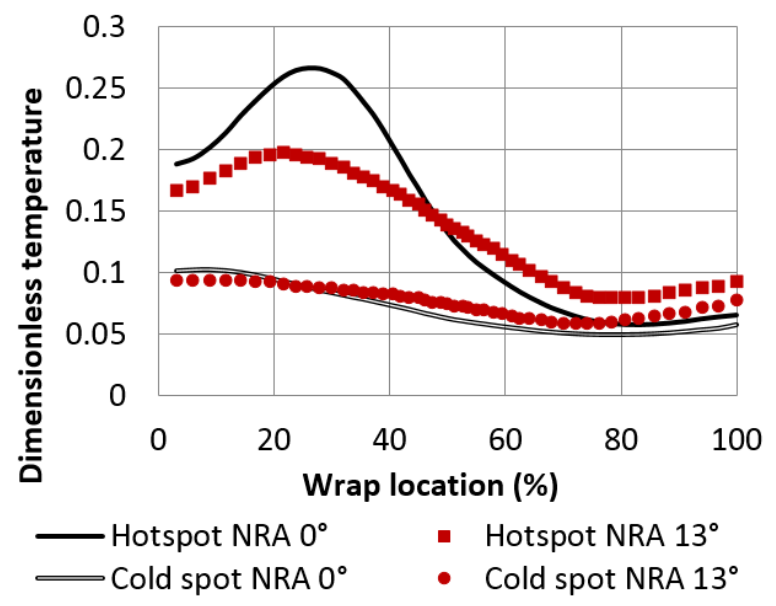

Fig. 13. The temperature distribution at NRA $13^{\circ}$ in hotspot and cold spot planes.

Rotating the nozzle towards the inner skin increases the spacing-nozzle-to-impinging-area. Consequently, the air mixing process is enhanced, due to increasing heat and momentum during the exchange between the hot jet and the stagnant cold air in the D-chamber. Thus, both the heat transfer coefficient $(h)$ on the impinging point, and the hotspot temperature, decrease. Therefore, the hotspot $\dot{\boldsymbol{T}}$ is inversely proportional to the NRA, as illustrated in Fig. 12. In the meantime, the stagnation cold air inside the D-chamber receives more heat and momentum from the hot air in the nozzle. Subsequently, this cold air has a higher average temperature and Mach number to flow around D-chamber nacelle lip-skin. It is well known that the heat transfer coefficient increases with increasing hot air velocity. As a consequence, the average $\dot{\boldsymbol{T}}$ of nacelle lip-skin increases as the NRA increases, up to $13^{\circ}$. Since the average velocity of the stagnation air in the D-chamber increases, the lowest air velocity inside the D-chamber increases as well, as illustrated in Fig 14. Thus, the lowest heat transfer coefficient from air to nacelle lip-skin also increases. Therefore, as illustrated in Fig.12, the cold-spot $\dot{\boldsymbol{T}}$ increases with increasing NRA.

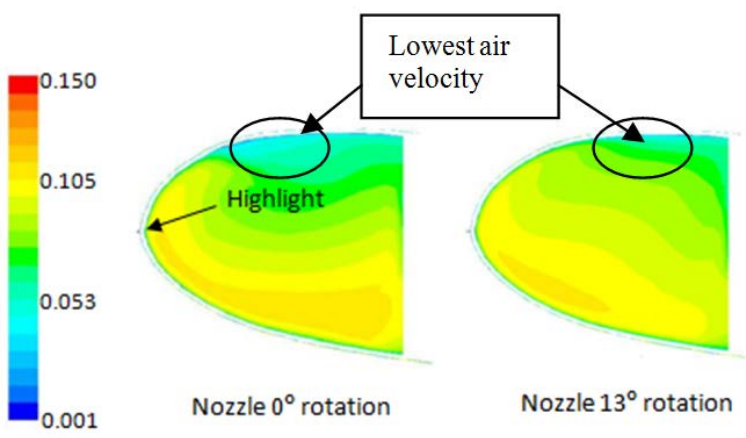

Fig. 14. Mach number contour in Plane $90^{\circ}$

\subsection{Effect of nozzle sizes on SAI performance}

The effect of the nozzle sizes on the SAI thermal performance will be analyzed in this section. The study investigated the effects of 3 different nozzle ratio areas ( $\left.A_{\text {nozzle }} / A_{D \text {-chamber }}\right)$ of $0.02088,0.04699$, and 0.08354 , on the SAI thermal performance at the $\dot{m}_{\text {nozzle }}$ of $0.08354 \mathrm{~kg} / \mathrm{s}$.

Figure 15 shows the lip-skin dimensionless temperature contours for three different nozzle ratio areas at the $\dot{\boldsymbol{m}}_{\text {nozzle }}$ and $T_{\text {nozzle }}$ of $0.04536 \mathrm{~kg} / \mathrm{s}$ and $533 \mathrm{~K}$, respectively. The hotspots occur in plane $178^{\circ}$ for nozzles with nozzle ratio areas of 0.02088 and 0.04699 , and in plane $175^{\circ}$ for the nozzle ratio area of 0.08354 . The figure shows that the antiicing performance on the nacelle lip-skin deteriorates significantly as the nozzle ratio area increases. The $T_{h i}$ values are $0.4757,0.4959$, and 0.5097 for nozzle ratio areas of $0.02088,0.04699$, and 0.08354 , respectively. According to Fig. 15 and Fig. 16, the cold-spot $\dot{T}$ and the average $\dot{T}$ decrease as the nozzle ratio area increases. The increase in the hotspot $\dot{T}$, and the decrease in the cold-spot $\dot{T}$ and the average $\dot{T}$ by $30.2 \%$ and $29.2 \%$, respectively, with increasing $\boldsymbol{A}_{\text {nozzle/AD-chamber }}$ ratio, proves that the swirl anti icing performance deteriorates with increasing ratio nozzle area. 


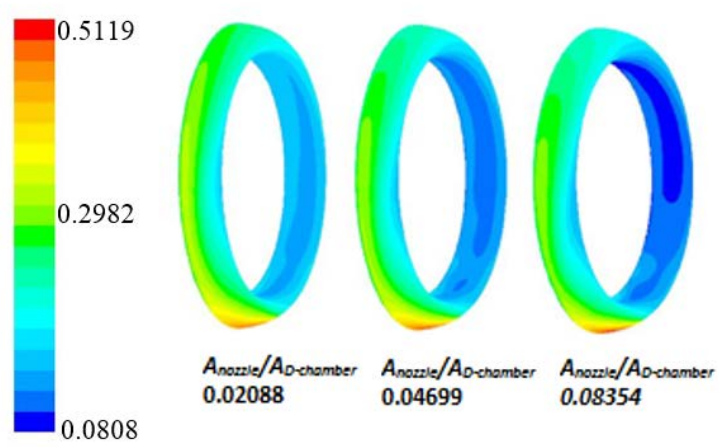

Fig. 15. Lip-skin temperature contours at different nozzle ratio areas

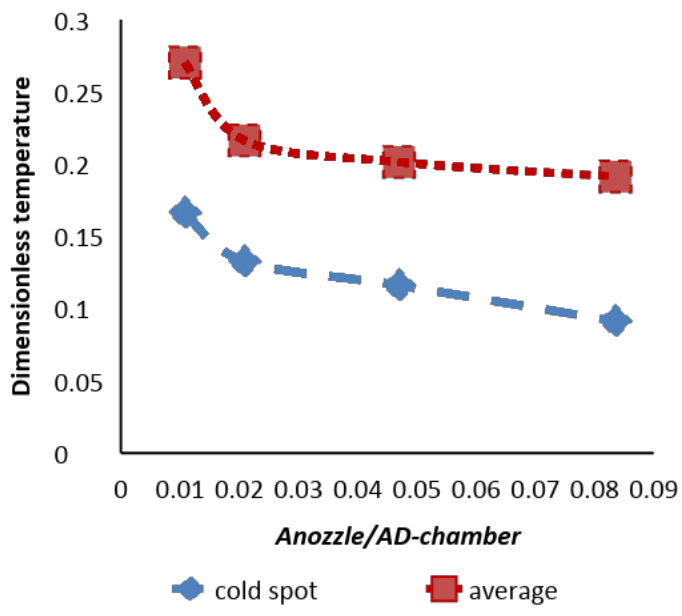

Fig. 16. Dimensionless temperature at different nozzle diameter ratios

A potential reason for the hotspot $\dot{\boldsymbol{T}}$ increases with increasing nozzle ratio area is that the ratio of distance between the nozzle and the impinging spot, to the nozzle diameter $(Z / d)$, decreases with increasing $A_{\text {nozzle }} / A_{D-\text { chamber }}$ ratio. According to the calculations, $A_{\text {nozzle }} / A_{D-\text { chamber }}$ ratios of $0.02088,0.04699$, and 0.08354 , Z/d ratios of $17.2 d, 11.5 \mathrm{~d}$, and $8.7 d$, respectively, where $d$ is the nozzle diameter. Raghunathan et al. [17] state that the optimum heat transfer rate on the impingement surface occurs at $Z / d$ values ranging from $5 d$ to $7 d$. At $Z / d$ values exceeding $7 d$, the local heat transfer coefficient decreases. The $A_{\text {nozzle }} / A_{D \text {-chamber }}$ ratio of 0.08354 corresponds to the $Z / d$ value of $8.7 d$, which is the closest to the optimum $Z / d$ ratio. The nozzle $A_{\text {nozzle }} / A_{D \text {-chamber }}$ ratio of 0.02088 should yield the lowest hotspot $\dot{T}$ in this study, having the' highest $Z / d$ value. This is coincident with the results being published by another researcher on nacelle lip-skin anti-icing.

\subsection{Relationship between Average Reynolds number and Average Nusselt number for different NRA and Sizes}

The correlation between the Reynolds number and the Nusselt number in the present work is summarized in Fig. 17. Table 2 shows the legend for the nozzle ratio area and the rotation angle, in order to simplify the following discussion.
The average Reynolds number $\left(R e_{\text {ave }}\right)$ used in this study is described by the following formula:

$$
R e_{a v e}=\frac{\dot{m}_{s w} D_{h}}{A_{D-c h a m b e r} \mu}
$$

$\dot{m}_{s w}$ in the present study is estimated by using Eq. (3):

$$
m_{s w}=\rho_{f} A_{D-C h a m b e r} V_{S W}
$$

Since the D-chamber is a non-circular duct, the $D_{h}$ of the Dchamber was estimated by using Eq. (4):

$$
D_{h} \equiv \frac{4 A_{D-\text { Chamber }}}{P_{W}}
$$

Eq. (5) is used to estimate $h_{\text {ave }}$ :

$$
h_{a v e}=\frac{q_{a v e}}{T_{b}-T_{a v e}}
$$

Table 2. Legend of the nozzle models

\begin{tabular}{c|c|c|c}
\hline Models & Nozzle type & $\begin{array}{c}\boldsymbol{A}_{\text {nozzle }} / \boldsymbol{A}_{\boldsymbol{D}-} \\
\text { chamber }\end{array}$ & NRA $\left(^{\circ}\right)$ \\
\hline Model A & Circle nozzle & 0.01083 & 0 \\
Model B & Circle nozzle & 0.01083 & 13 \\
Model C & Circle nozzle & 0.02088 & 0 \\
Model D & Circle nozzle & 0.04699 & 0 \\
Model E & Circle nozzle & 0.08354 & 0 \\
\hline
\end{tabular}

The relationship between the average Nusselt number $\left(N u_{a v e}\right)$ and the $R e_{\text {ave }}$ for Nozzles $\mathrm{A}$ to $\mathrm{E}$ is shown in Fig. 17. The $N u_{a v e}$ in the figure is determined by using Eq. (6):

$$
N u_{a v e}=\frac{h_{a v e} D_{h}}{k_{f}}
$$

The figure shows that $N u_{s w}$ is proportional to $\operatorname{Re}_{s w}{ }^{0.947} \mathrm{Pr}^{1 / 3}$. In fact, $N u_{s w}$ is related to $h_{s w}$ (see Eq. 6). Since nozzle types do not have big effect on $h_{s w}$, nozzle types also do not affect $N u_{s w}$. Thus, Nozzles A to E follow the similar $N u_{s w}$ vs. $R e_{s w}$ profile as shown in the figure. The relationship between $\mathrm{Nu}$ and $R e$ for smooth, long tube and fully develop flow, is expressed as follows:

$$
N u=A R e_{d}^{B} \operatorname{Pr}^{C}
$$

According to Dittus and Boelter [18], the coefficient of $C$ in Eq. 7 is $1 / 3$ because the heat is transferred from the hot air in D-chamber to nacelle lip-skin. By using the least square methods, the most appropriate value of $B$ in Eq. 7 is 0.947 . Finally, $A$ has been determined by taking the gradient $N u_{s w}$ vs. $\operatorname{Re}_{s w}{ }^{0.947} \operatorname{Pr}^{1 / 3}$ as shown in Fig. 17. Therefore, the empirical correlation of $N u_{s w}$ vs. $R e_{s w}$ for SAI, given ambient condition is defined in Eq. 8.

$$
N u_{a v e}=0.0055 \operatorname{Re}_{a v e}^{0.947} \operatorname{Pr}^{1 / 3}
$$




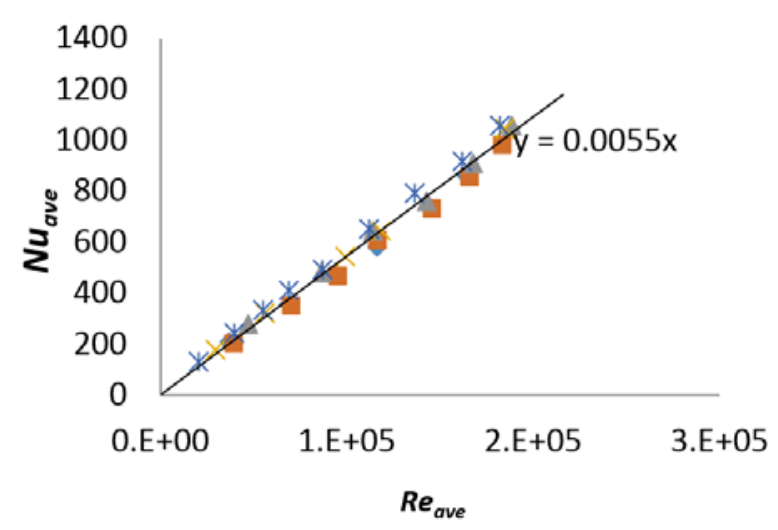

- Nozzle A $⿴$ Nozzle B $\triangle$ Nozzle C $\times$ Nozzle D $*$ Nozzle E

Fig. 17. $N u_{\text {ave }}$ against $R e_{\text {ave }}$ for various nozzle diameters and outlet shapes.

\section{Conclusion}

The SAI system's heat transfer characteristic and its' potential improvement are investigated and discussed in this paper. In general, the outer skin has a higher temperature than the inner skin, since the swirling air velocity and the temperature in the D-chamber close to the outer skin are higher than those in the D-chamber close to the inner skin. Seeking to develop an alternative design, the NRA has been studied, to enhance the SAI anti-icing system's thermal performance. The NRA towards the inner skin results in the most significant improvement in the SAI's thermal performance. The hotspot $\dot{\boldsymbol{T}}$ decreases by 0.06947 and the cold-spot $\dot{\boldsymbol{T}}$ increases by 0.00938 as the nozzle is rotated from $0^{\circ}$ to $13^{\circ}$ towards inner skin, at the $\dot{\boldsymbol{m}}_{\text {nozzle }} / A_{D \text {-chamber }}$ ratio of $1.94 \mathrm{~kg} / \mathrm{m}^{2} \mathrm{~s}$. The anti-icing system's performance deteriorates with increasing nozzle size. The hotspot $\dot{\boldsymbol{T}}$ increases by 6.7\%; and cold-spot $\dot{\boldsymbol{T}}$ and average $\dot{\boldsymbol{T}}$ decrease by $30.2 \%$ and $29.2 \%$, respectively, as the nozzle ratio area increased from 0.01083 to 0.08354 . Finally, $N u_{\text {ave }}$ is proportional to $R e_{\text {ave }}$ as Eq. (8) indicates.

$$
N u_{s w}=0.0055 e_{s w}^{0.947} \operatorname{Pr}^{1 / 3}
$$

\section{Acknowledgements}

The authors would like to thank Universiti Sains Malaysia for sponsoring this research under Grant codes 304.PMEKANIK.6316099 and 304.PMEKANIK.6315150

\begin{tabular}{|c|c|}
\hline$\dot{\boldsymbol{m}}_{s w}$ & =Average air mass flow rate in D-chamber \\
\hline$\dot{\boldsymbol{m}}_{\text {nozzle }}$ & = Hot air injection mass flow rate \\
\hline$A_{D \text {-chamber }}$ & $=$ D-chamber cross-sectional area \\
\hline$A_{\text {nozzle }}$ & $=$ Nozzle cross-sectional area \\
\hline$\dot{T}$ & = Dimensionless temperature \\
\hline$Z / d$ & = ratio of distance between nozzle and \\
\hline & impinging spot, to nozzle diameter \\
\hline$d$ & = Nozzle diameter \\
\hline$R e_{a v e}$ & = Average Reynolds number \\
\hline$N u_{a v e}$ & = Average Nusselt number \\
\hline$R e$ & = Reynolds number \\
\hline $\mathrm{Nu}$ & = Nusselt number \\
\hline$\rho_{f}$ & = Average air density \\
\hline$T_{\text {ave }}$ & = Average lip-skin temperature \\
\hline$h$ & = Heat transfer coefficient \\
\hline$h_{\text {ave }}$ & = Average heat transfer coefficient \\
\hline$v_{j}$ & = Jet velocity \\
\hline$v_{s w} \boldsymbol{V}_{\boldsymbol{S W}}$ & = Average air velocity inside D-chamber \\
\hline$D_{h}$ & = Hydraulic diameter \\
\hline$P_{w}$ & = Wetted perimeter \\
\hline qave & = Average heat flux of nacelle lip-skin \\
\hline $\mathrm{kf}_{\mathrm{f}}$ & $=$ Thermal conductivity of fluid \\
\hline $\operatorname{Pr}$ & $=$ Prandtl number \\
\hline$\mu$ & = Dynamic viscosity of fluid \\
\hline
\end{tabular}


[1] J. L. Lucas, "Integrated nacelle inlet and metallic fan containment case," ed: Google Patents, 2017.

[2] A. Ives, "Perforated honeycomb acoustic liner heat transfer," Queen's University Belfast, 2010.

[3] G. S. Baruzzi et al., "Multi-physics Simulation of Aircraft Ice Protection System and Ice Impact with Turbofan Blades," in 8th AIAA Atmospheric and Space Environments Conference, 2016, p. 4353.

[4] "Swirl anti-ice system," ed: Google Patents, 1987.

[5] Keith, Jr, Theo G, K. J. Dewitt, J. K. Nathman, D. A. Dietrich, and K. M. Al-Khalil, "Thermal analysis of engine inlet anti-icing systems," Journal of Propulsion and Power, vol. 6, no. 5, pp. 628-634, 1990.

[6] U.-H. Jung, S. Kim, K.-H. Jeong, J.-H. Kim, K.-Y. Lee, and Y.-S. Choi, "Numerical study on performance improvement when strong vortex occurs on the shroud of vaneless diffuser in turbo blower," Journal of Mechanical Science and Technology, vol. 30, no. 6, pp. 2515-2529, 2016.

[7] A. Smith and K. Taylor, "The Simulation of an Aircraft Engine Intake Anti-Icing System," phoenics journal of computational fluid dynamics and its applications, vol. 10, pp. 150-166, 1997.

[8] J. Hua and H. H. Liu, "Fluid flow and thermodynamic analysis of a wing anti-icing system," Canadian Aeronautics and Space Journal, vol. 51, no. 1, pp. 3540, 2005.

[9] P. Planquart, G. V. Borre, and J.-M. Buchlin, "Experimental and numerical optimization of a wing leading edge hot air anti-icing system," AIAA paper, vol. 1277, p. 2005, 2005.

[10] M. Papadakis and S. Wong, "Parametric investigation of a bleed air ice protection system," AIAA paper, vol. 1013, p. 2006, 2006.

[11] S.-H. Wong, M. Papadakis, and A. Zamora, "Computational Investigation of a Bleed Air Ice Protection System," AIAA paper, vol. 3966, 2009.

[12] J.-O. Mo and Y.-H. Lee, "CFD Investigation on the aerodynamic characteristics of a small-sized wind turbine of NREL PHASE VI operating with a stallregulated method," Journal of Mechanical Science and Technology, vol. 26, no. 1, pp. 81-92, 2012.

[13] Q. Azam, M.-A. Ismail, N.M.Musfirah, and M.Bashir et al. "Numerical Comparison of Drag Coefficient between Nacelle Lip-Skin with and without Bias Acoustic Liner." International Review of Mechanical Engineering (IREME) 10.6 (2016): 390-394.

[14] H. Rosenthal and D. Nelepovitz, "Performance of a new nose-lip hot-air anti-icing concept," in AIAA, SAE, ASME, and ASEE, Joint Propulsion Conference, 21 st, Monterey, CA, 1985.

[15] Y. G. Motlagh and H. T. Ahn, "Laminar and turbulent channel flow simulation using residual based variational multi-scale method," Journal of Mechanical Science and Technology, vol. 26, no. 2, pp. 447-454, 2012.

[16] D. C. Wilcox, Turbulence modeling for CFD. DCW industries La Canada, CA, 1998.

[17] S.Rahunathan, E. Bernard, J.K.Watterson, R.K.Coopper, R. Curran, M.Price, H.Yao, R. Devine, B. Crawford, D. Riordan, A. Linton, J. Richardson and J. Tweedle, "Key aerodynamic technologies for aircraft engine nacelle", The Aeronautical Journal, Vol.110, no.17, pp.265-288, 2006.

[18] F. P. Incropera and D. P. Dewitt "Fundamental of Heat and Mass Transfer, fourth edition”, s.l.:John Willey \& Sons, pp. 347-389, 1994.

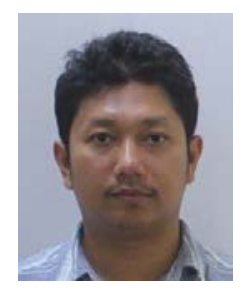

Mohd Azmi Ismail received Bachelor's and Master's Degrees in Mechanical Engineering from Universiti Sains Malaysia, Engineering campus, Nibong Tebal, Penang, Malaysia. He obtained a Doctoral Degree from Kingston University, United Kingdom. $\mathrm{He}$ is received funds under research grants from various research organizations. He has published articles in national and international level journals and conference proceedings. He is a professional member of the Board of Engineering Malaysia. His areas of expertise are electronic cooling, Anti-Icing, Spillway dams, CFD, and AirConditioning

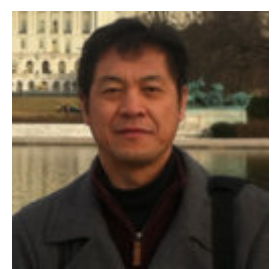

Jian Wang is a professor in Kingston University London. He is received funds under research grants from various research organizations. He has published articles in national and international level journals and conference proceedings. His areas of expertise are Aircraft design, Anti-Icing and CFD. 